Article

\title{
Application of Trichoderma spp. Complex and Biofumigation to Control Damping-Off of Pinus radiata D. Don Caused by Fusarium circinatum Nirenberg and $O^{\prime}$ Donnell
}

\author{
Carmen Morales-Rodríguez, Giorgia Bastianelli, MariaPia Aleandri, Gabriele Chilosi \\ and Andrea Vannini * (1)
}

Department for Innovation in Biological, Agro-food and Forest Systems (DIBAF), Agriculture and Forestry Campus, University of Tuscia, Via S. Camillo de Lellis, 01100 Viterbo, Italy; moralescorreo@hotmail.com (C.M.-R.); giorgiabastianelli93@gmail.com (G.B.); aleandri@unitus.it (M.A.); chilosi@unitus.it (G.C.)

* Correspondence: vannini@unitus.it; Tel.: +39-320-4363554

Received: 1 June 2018; Accepted: 11 July 2018; Published: 12 July 2018

\begin{abstract}
The damping-off of Pinus radiata D.Don by Fusarium circinatum Nirenberg and O'Donnell represents a limiting factor in nursery production, while seed contamination with the pathogen is one of the main pathways of the pathogen movement between areas. Chemical and physical treatments have been applied with encouraging results and some limitations. In the present study, biocontrol of damping-off by F. circinatum is proposed with Trichoderma spp. complex showing complementary antagonism and biofumigation with commercial Brassica carinata A. Braun pellets with biocidal effect. Experiments were conducted in vitro and in vivo using batches of $P$. radiata seeds and two $F$. circinatum isolates. Results were highly positive, showing an excellent efficacy of a combination of Trichoderma spp. in a single preparation to reduce significantly the mortality of $P$. radiata seedlings in seeds bed experiment. Biofumigation with $B$. carinata pellets also showed efficacy in controlling the $F$. circinatum inoculum and reducing seed mortality in inoculated seed batches although showing some phytotoxic effect.
\end{abstract}

Keywords: biological control; pitch canker; Pinus radiata; antagonism; isothiocyanates

\section{Introduction}

Fusarium circinatum Nirenberg and $\mathrm{O}^{\prime}$ Donnell is the causal agent of pitch canker, which affects Pinus spp. and Pseudotsuga menziesii (Mirb.) in many countries worldwide [1,2]. In trees, F. circinatum causes branch dieback and resinous cankers that progressively girdle the wood, causing branch death. Canker infection of multiple branches of the main stem can cause extensive dieback in the tree crown, which can lead to tree mortality [3]. This disease causes significant economic losses in mature plantations because of reduced growth, quality of the timber, and tree mortality [4]. In nurseries, pitch canker is also an important disease associated with damping-off, shoot and tip dieback, and death of seedlings [5]. F. circinatum may contaminate pine seeds superficially or infect them in a latent or active form [6-9]. The presence of F. circinatum as a superficial inoculum or internal infection is likely to affect the efficacy of the seed treatments, as surface disinfection may not be sufficient. The pathogen can also asymptomatically infect the seedlings, although most of the infected seedlings will eventually develop the disease and die in nurseries [6]. Furthermore, the movement and trade of contaminated seed and seedlings is an important mechanism of the introduction of the pathogen into new areas [10,11], as it has been reported to occur in Chile [12], South Africa [12], and Spain [11]. Currently, the use of 
pesticides or hot water seed treatments, with quarantine and hygiene practices, are the methods mostly used to mitigate the risk of disease emergence on seedlings in nurseries [9]. However, increasing restrictions on the utilization of synthetic pesticides and their effects on the environment and human health [13], have raised interest in alternative methods to control pitch canker in nurseries.

Fungi such as Trichoderma spp. are widely used as biological control agents (BCAs) because of their ability to reduce the incidence of disease caused by common plant pathogenic fungi [14]. The degree of protection provided by Trichoderma spp. can be as effective as fungicide applications [15]. Trichoderma spp. utilize mycoparasitism [16] and antibiosis [17] as biocontrol mechanisms. Various Trichoderma strains with complementary antagonistic effects can be mixed as a complex in the treatment of soil-borne plant pathogens. Aleandri et al. [18] suggested that a complex of Trichoderma spp. activates systemic resistance in the host plants. Martin-Pinto et al. [19] suggested that Trichoderma spp. might exert antagonistic effects on nursery diseases caused by Fusarium spp. In the case of Pinus radiata D. Don (Monterey Pine) and pitch canker, several studies have been conducted with a number of isolates of Trichoderma spp., in order to evaluate the efficacy in mitigating the impact of the pathogen [20,21]. Studies with T. hamatum (Bonord.) Bainier, T. viride Pers., and T. atroviride P. Karst, produced encouraging results, although antagonism was always variable depending on the pathogen genotype and host plant $[20,22,23]$.

Biofumigation refers to the suppression of soil-borne pests and pathogens by biocidal compounds released by species of Brassicaceae when glucosinolates (GLs) in their tissues are hydrolyzed by the myrosinase enzyme [24]. Hydrolysis products of GLs, in particular, the isothiocyanates (ITCs), are known to have broad biocidal activity, including insecticidal, nematicidal, fungicidal, antibiotic, and phytotoxic effects [25]. Some ITCs are characterized by high volatility and could potentially be applied as gaseous treatments to fruit and vegetables through 'biofumigation', commonly used for soil-borne pest control [26]. The efficacy of ITCs has been demonstrated in post-harvest treatment against several pathogens, such as Alternaria alternata (Fr.) Keissl., Botrytis cinerea Pers., and Colletotrichum acutatum J. H. Simmonds on blueberry fruit [27], or B. cinerea on strawberries [28]. The ITCs released from the Brassicaceae species have been shown to be useful in controlling Fusarium oxysporum Schltdl., a soil-borne pathogen of conifer seedlings in the nursery [29].

The objectives of this work are (1) to investigate in vitro the mechanisms of the antagonisms of Trichoderma spp. against the pathogen F. circinatum; (2) to test the efficacy of a combination of Trichoderma spp. in reducing the incidence of damping-off by soil-borne F. circinatum in vivo in the seedbeds of $P$. radiata; (3) to conduct in vitro studies to monitor the effect of biofumigation with ITCs on the mycelial growth and conidia germination of F. circinatum; and (4) to evaluate the efficacy of biofumigation of $P$. radiata seed as a preventive treatment to mitigate the risk of pitch canker occurrence and the establishment of F. circinatum infections upon the movement and trade of contaminated seeds.

\section{Materials and Methods}

\subsection{Fusarium and Trichoderma Isolates}

Two F. circinatum isolates were used in this study, FcCa1 and Fc015 [22], obtained from a branch and the xylem tissue of $P$. radiate, respectively, belonging to the collection of the Sustainable Forest Management Research Institute (University of Valladolid-INIA, Valladolid, Spain) in Cantabria (Spain).

As antagonists, four isolates of Trichoderma spp. belonging to the collection of the Department for Innovation in Biological, Agro-food, and Forest systems (DIBAF, Tuscia University, Viterbo, Italy) were used. The isolates used were T. hamatum T3, T. harzianum Rifai T6, T. asperellum Samuels, Lieckf. and Nirenberg T20, and T. virens (J. H. Mill., Giddens and A. A. Foster) Arx T21. The antagonism and induction of resistance of these isolates, alone or in combination, were previously reported by Aleandri et al. [18]. 


\subsection{Microscopic Identification of F. circinatum}

For morphological fungal identification, putative colonies of F. circinatum were grown on a Spezieller Nahrstoffarmer Agar (SNA) medium to confirm the species. The plates were incubated for 7-10 days at $25^{\circ} \mathrm{C}$ and then microscopically inspected for the formation of a coiled sterile hyphae, characteristic of F. circinatum [30].

\subsection{Biocontrol of F. circinatum by Trichoderma spp.}

2.3.1. In Vitro Assessment of Antagonistic Activity by Dual Culture Assay and Antibiosis by Non-Volatile and Volatile Metabolites

Dual culture inhibition experiments, as described by Morton and Stroube [31], were performed in order to determine the direct antagonistic activity, as well as the production of antifungal non-volatile and volatile metabolites of Trichoderma isolates against F. circinatum. Mycelial discs (6 mm in diameter) obtained from the peripheral region of the growing colonies of both the Trichoderma spp. and F. circinatum isolates were paired in all possible combinations on potato dextrose agar (PDA), approximately $1 \mathrm{~cm}$ from the edge of the $9 \mathrm{~cm}$ diameter Petri plates. The Petri plates inoculated with F. circinatum alone served as the control. The plates were incubated at $25^{\circ} \mathrm{C}$, and measurements were taken after five days. At the end of the incubation period, the radial growth was measured and the inhibition of the average radial growth was calculated in relation to the growth of the controls [32]. The experimental design was a randomized block with ten replicated plates per Trichoderma-pathogen combination, and the assay was repeated twice.

For the non-volatile metabolites assessment, each Trichoderma isolate was inoculated into $100 \mathrm{~mL}$ of potato dextrose broth (PDB) at $25^{\circ} \mathrm{C}$ for 10 days. After incubation, the cultures were filtered through $0.22 \mathrm{~mm}$ filters (Merck Millipore, Darmstadt, Germany). Then, $1 \mathrm{~mm}$ aliquots of the filtrates were placed in sterile Petri plates, and $25 \mathrm{~mL}$ of PDA at $50{ }^{\circ} \mathrm{C}$ were added. After solidification, a mycelial disc of each pathogen isolate $(6 \mathrm{~mm}$ in diameter), obtained from actively growing colonies, was placed in the center of the plate. The assay was repeated twice.

The effect on the F. circinatum mycelial growth of the volatile metabolites that were released by the Trichoderma isolates was evaluated according to Dennis and Webster [33]. The PDA plates were inoculated centrally with mycelial disks of Trichoderma isolates, and the lid of each plate was replaced with a dish containing PDA inoculated with each $F$. circinatum isolate. The two plates were taped together and the growth of F. circinatum was recorded after $72 \mathrm{~h}$. In the controls, the F. circinatum isolates were cultured in the absence of the Trichoderma isolates. The assay was repeated twice.

For both the non-volatile and volatile metabolites tests, the percent inhibition was calculated in relation to the growth of the controls, as described by Lahlali and Hijri [32].

\subsubsection{Biocontrol Activity against F. circinatum in the Seedbed of $P$. radiata}

The seeds of $P$. radiata were artificially inoculated with conidial suspensions of $F$. circinatum isolates, using the procedure described by Ioos et al. [34]. Firstly, the seeds were surface disinfected by soaking for $10 \mathrm{~min}$ in a solution containing $0.37 \% \mathrm{NaHClO}$ and $0.1 \%$ Tween-20, followed by complete drying on a sterile filter paper in a laminar flow hood. The conidial suspensions of isolates FCCa1 and Fc015 were adjusted to a concentration of $2 \times 10^{6}$ conidia $\mathrm{mL}^{-1}$. The seeds were inoculated by soaking separately in a conidial suspension of each isolate amended with $0.1 \%$ Tween-20 for 10 min, after which they were air-dried overnight in a laminar flow hood. Two batches of 10 inoculated seeds per isolate were cultured on a Komada medium [35] after $24 \mathrm{~h}$ of imbibing the water. The F. circinatum was observed to grow from $100 \%$ of the seeds, confirming that soaking the inoculated seeds for the imbibition process would not remove all of the conidia from the seed surface.

A combination of the four isolates of Trichoderma spp. (T-complex) was used as the biocontrol inoculum. The substrate for the T-complex inoculum was prepared using millet kernels, which were imbibed with sterilized $\mathrm{H}_{2} \mathrm{O}$ in $250 \mathrm{~mL}$ Erlenmeyer flasks (50 g of millet kernels each flask) and 
autoclaved twice for $30 \mathrm{~min}$ at $121{ }^{\circ} \mathrm{C}$. Each flask was inoculated with 10 agar discs $(6 \mathrm{~mm}$ in diameter), cut from the edge of actively growing cultures of Trichoderma spp., and incubated for 10 days at $23^{\circ} \mathrm{C} \pm 2{ }^{\circ} \mathrm{C}$. The four isolates of Trichoderma spp. were inoculated each in a distinct flask. The T-complex was prepared by mixing equal amounts of inoculum of each of the Trichoderma isolates. The potting mix for the P. radiata seeds consisted of peat (grain size $10-30 \mathrm{~mm}$, organic carbon $10 \%$ dry weight (dw), organic nitrogen $0.7 \mathrm{dw}$, organic matter $96 \% \mathrm{dw}$, and $\mathrm{pH}$ 3.5; Vigorplant, Lodi, Italy), pumice (1:1 containing $2 \mathrm{~kg} / \mathrm{m}^{3}$ lime), and Osmocote 10-11-18 NPK (Scotts Italia Ltd., Treviso, Italy). Before use, the potting mix was sterilized twice at $121^{\circ} \mathrm{C}$ for $15 \mathrm{~min}$. The inoculation of the potting mix was carried out with $3 \mathrm{~g} \mathrm{Kg}^{-1}$ of T-complex, corresponding to approximately $2.5 \times 10^{9}$ spores $\mathrm{Kg}^{-1}$.

For the experiment, batches of forty seeds were placed in plastic seed trays. Each cell of the tray received $25 \mathrm{~mL}$ of potting mix and one seed. The treatments consisted of (1) uninoculated seeds in the potting mix without the T-complex; (2) uninoculated seeds plus potting mix with the T-complex; (3) inoculated seeds with F. circinatum in the potting mix without the T-complex; and (4) inoculated seeds with F. circinatum plus potting mix, with the T-complex. Treatments (3) and (4) were duplicated using each of the two F. circinatum isolates, $\mathrm{FcCa}_{\mathrm{C}}$ and $\mathrm{F}_{\mathrm{C}} 015$. Thus, a total of eight treatments per three replicates each, wa considered. The seed trays were maintained in a growth chamber at $25^{\circ} \mathrm{C}$, with a photoperiod of $16 \mathrm{~h}$ of light and $8 \mathrm{~h}$ of darkness. The percentage of seeds' germination was recorded 15 days after sowing; the seedling mortality was recorded after two months, from the germinated/remained seeds.

\subsection{Biocontrol of F. circinatum with Biofence ${ }^{\circledR}$}

\subsubsection{In Vitro Inhibition Tests}

Brassica pellets, BioFence ${ }^{\circledR}$ (Triumph Italia SPA), were used as a seed treatment in this study, as it is a low cost, commercially available, easy to use, and environmentally friendly product. BioFence ${ }^{\circledR}$ is produced from B. carinata A. Braun selection ISCI 7, using a proprietary partial de-fatting method that limits glucosinolate and myrosinase degradation [36].

The inhibition tests were conducted using BioFence ${ }^{\circledR}$ in powder, according to the protocol described by Morales-Rodríguez et al. [37]. Six biofumigant concentrations (0, 0.850, 0.17, 0.34, 0.68 , and $\left.1.37 \mathrm{~g} \mathrm{~L}^{-1}\right)$ for radial growth assessment and seven concentrations $(0,0.125,0.25,0.5,0.75,1$, and $2 \mathrm{~g} \mathrm{~L}^{-1}$ ) for conidia germination assessment were compared at two different temperatures (10 and $20{ }^{\circ} \mathrm{C}$ ) [37]. For each of the tests, there were five replicate plates per treatment combination. All of the in vitro experiments were repeated twice.

\section{Mycelial Inhibition}

Mycelial disks $(6 \mathrm{~mm})$ from actively growing colonies of the two $F$. circinatum isolates were placed in the center of a PDA plate $(9 \mathrm{~cm})$. All of the plates were incubated at $25{ }^{\circ} \mathrm{C}$ for $48 \mathrm{~h}$ before being exposed to the biofumigation, in order to exclude the initial growth lag phase.

\section{Conidia Germination}

The F. circinatum isolates were grown on PDA and incubated for 15 days at $25{ }^{\circ} \mathrm{C}$ in the dark. The conidial suspensions from each isolate were prepared by flooding the agar surface with approximately $15 \mathrm{~mL}$ of sterile distilled water (SDW) and scraping with a sterile spatula. The resulting suspension was filtered through two layers of cheesecloth and adjusted with SDW to 100 conidia $\mathrm{mL}^{-1}$, and $1 \mathrm{~mL}$ aliquot spread over a Petri plate containing a Komada medium.

The biofumigant was placed on the lids of the plates and inoculated either with a mycelium plug or a conidia suspension. The plates with no biofumigant treatments were used as controls. The biofumigation was started by moistening the pellet with SDW $\left(1 \mu \mathrm{L} \mathrm{mg}{ }^{-1}\right.$ of pellet). The plates were immediately sealed with Parafilm ${ }^{\circledR}$ and incubated inverted (lid on the bottom) in the dark at each temperature. To evaluate the efficacy of the biofumigation, the radial growth of the colonies 
(mean of two perpendicular diameters) was recorded after six days. The lids of the plates with $100 \%$ inhibition were removed at the end of the experiment and were replaced with new lids without the biofumigant. The plates were maintained for another 30 days at $25{ }^{\circ} \mathrm{C}$, in order to evaluate the fungicidal or fungistatic effect of the biofumigant. The conidia were treated with BioFence ${ }^{\circledR}$ for $24 \mathrm{~h}$ at each temperature $\left(10\right.$ or $\left.20^{\circ} \mathrm{C}\right)$ after the biofumigant was removed, and the plates were incubated at $20{ }^{\circ} \mathrm{C}$ to permit the conidia germination. The number of colony forming units (CFUs) from the conidial suspensions was assessed after eight days. The plates were maintained for one month at $25^{\circ} \mathrm{C}$, to evaluate the fungicidal or fungistatic effect of the biofumigant. To calculate the percent inhibition, the radial growth/germination in the presence of the biofumigant material was expressed as the mean percentage of the growth/germination in the control plates.

\subsubsection{Effect of Biofumigation Exposure Period on F. circinatum In Vitro}

The exposure period to obtain a fungicidal effect of BioFence ${ }^{\circledR}$ on F. circinatum was studied by exposing the mycelium and conidia to biofumigant doses for $3 \mathrm{~h}, 6 \mathrm{~h}, 9 \mathrm{~h}, 24 \mathrm{~h}$, and $48 \mathrm{~h}$ at $10{ }^{\circ} \mathrm{C}$. The mycelial inhibition and conidia germination were assessed as reported in the previous paragraph. After the biofumigation, the lids of the plate were removed and substituted with a new one. The plates were incubated for one month at $20{ }^{\circ} \mathrm{C}$ so as to evaluate the fungicidal effect.

\subsubsection{Effect of Biofumigation with Biofence ${ }^{\circledR}$ to Control F. circinatum on P. radiata Seeds}

The Pinus radiata seeds were inoculated with conidial suspensions of F. circinatum isolates using the procedure described above [34]. The biofumigant and inoculated seeds were placed in hermetic plastic boxes $(10 \times 20 \mathrm{~cm}$ and $0.5 \mathrm{~L}$ in volume $)$ and incubated for $24 \mathrm{~h}$ at $10^{\circ} \mathrm{C}$. The dose recommended by the manufacturer, $3 \mathrm{~g} \mathrm{~L}^{-1}$, and a second, double dose $\left(6 \mathrm{~g} \mathrm{~L}^{-1}\right)$, were tested. The biofumigation was started by moistening the pellet with SDW $\left(1 \mu \mathrm{L} \mathrm{mg}{ }^{-1}\right.$ of pellet). After $24 \mathrm{~h}$ of biofumigation, the seeds were imbibed in water for $24 \mathrm{~h}$ and germinated in a wet chamber. Four replicates, of 30 seeds per treatment, and the F. circinatum isolate were performed. The germination percentage of the seeds and the F. circinatum growth were evaluated after 15 days in the wet chamber.

\subsection{Statistical Analyses}

All of the analyses were carried out with GraphPad Prism version 7.00 (GraphPad Software, San Diego, CA, USA) (http://www.graphpad.com/). The selection of the appropriate statistical analysis depended on the type of data obtained. In the absence of an interaction between the variables, two- or three-way ANOVA were chosen. In contrast, simpler datasets had to be considered, and the one-way ANOVA or unpaired $t$-test were chosen. The data homoscedasticity and departure from normality were tested with Bartlett's and D'Agostino-Pearson, respectively. Tukey's multiple comparison test was chosen as the post-hoc test. For the calculation of half maximal effective concentration $\left(\mathrm{EC}_{50}\right)$ the non-linear regression module 'agonist vs. response' of the GraphPad Prism version 7.00 was used where the 'dose' was the 'agonist', and the 'inhibition' was the 'response'. The model comparison was carried out with the extra sum of squares F-test function of the 'non-linear regression (curve fit)' module of GraphPad Prism version 7.00.

\section{Results}

\subsection{Biocontrol of F. circinatum by Trichoderma spp.}

3.1.1. In Vitro Assessment of Antagonistic Activity by Dual Culture Assay and Antibiosis by Non-Volatile and Volatile Metabolites

The results from the dual culture test demonstrated that all of the Trichoderma spp. inhibited the hyphal growth of F. circinatum (Figure 1). The percent inhibition of the hyphal growth by all of the Trichoderma isolates ranged between 43 and 60\%, and 45 and 64\% against isolates FcCa1 and Fc015, 
respectively. The two-way ANOVA highlighted a significant interaction between the two factors, the F. circinatum isolates and the Trichoderma spp. isolates $(F=9.36, p<0.05)$. Thus, a one-way ANOVA was run for each F. circinatum isolate. Significant differences between Trichoderma spp. on the extent of inhibition were found for each of the F. circinatum isolates (one-way ANOVA; $F=3.47$ and 40.09 for FcCa1 and Fc015, respectively, $p<0.05$ ). The T. asperellum (T20) showed the highest inhibition effect (\%) (55.9 \pm 04 and $58.9 \pm 0.6$ (SE) for FcCa1 and Fc015, respectively), while T. virens T21 was the least effective. Significant differences between the F. circinatum isolates $(\mathrm{FcCa} 1 \times \mathrm{Fc} 015)$ on the extent of the inhibition by Trichoderma spp. were found for T. viride, T. asperellum, and T. hamatum (unpaired $t$-test, $p<0.05)$, but T. harzianum ( $p>0.05)$. However, although significant, the differences in the inhibition of the F. circinatum isolates by Trichoderma spp. were small and difficult to interpret in a biological perspective. In the dual culture tests, all of the Trichoderma isolates displayed a faster growth than the Fusarium isolates (Figure 2). T. asperellum T20, T. hamatum T3, and T. harzianum T6 overgrew the F. circinatum isolates (Figure 2A,C,D,F), while T. virens T21 was separated from both of the F. circinatum isolates by a thick inhibition zone (Figure $2 \mathrm{~B}, \mathrm{G}$ ). F. circinatum $\mathrm{FcCa}$ 1 showed a pinkish phenotype when challenged with T. virens T21, T. hamatum T3, and T. harziamum T6 (Figure 2B-D). Both of the F. circinatum isolates, when challenged with T. asperellum T20, displayed an orangish phenotype (Figure 2A,C).
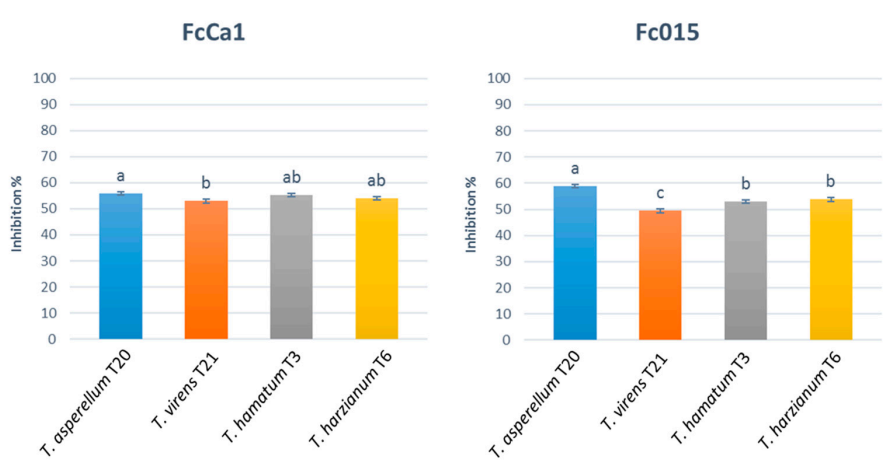

Figure 1. Percent inhibition of F. circinatum (FCCa1 and Fc015) mycelial growth in the dual test with Trichoderma spp. Different letters indicate significant differences at $p<0.05$, according to Tukey's post-hoc test. Vertical bars indicate standard error (SE).

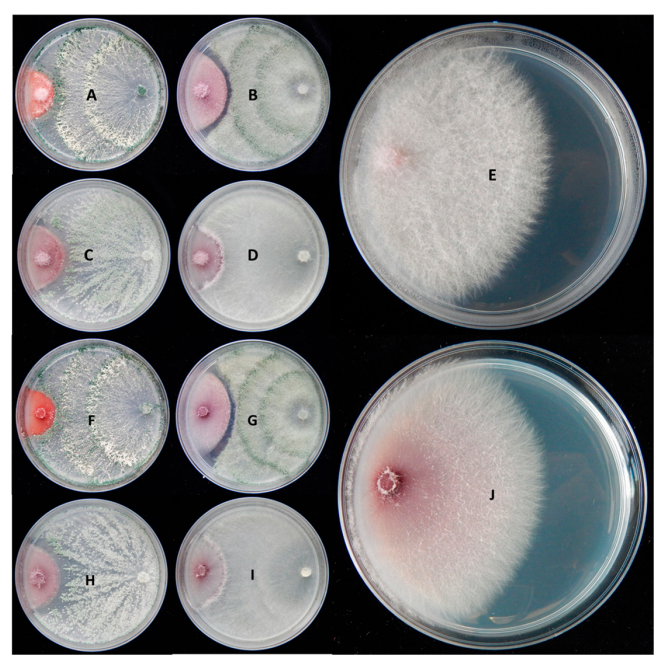

Figure 2. Dual culture tests between F. circinatum FcCa1 (A-E) and Fc015 (F-J). (A,F)-T. asperellum T20; (B,G)-T. virens T21; (C,H) - T. hamatum T3; (B,I)—T harzianum T6; (E) - control culture of FCCa1; (J) - control culture of Fc015. 
All of the Trichoderma spp. produced non-volatile inhibitory compounds, showing a variable inhibition activity of F. circinatum hyphal growth (Figure 3). The percent inhibition ranged from 17 to 37\% and 15 to 41\% for FcCa1 and Fc015, respectively. The two-way ANOVA highlighted a significant interaction between the two factors, the F. circinatum isolates and the Trichoderma spp. isolates $(F=48.74$, $p<0.05)$. Thus, one-way ANOVA was run for each of the F. circinatum isolates. Significant differences were found between Trichoderma spp. in the inhibition of the hyphal growth of both of the F. circinatum isolates (one-way ANOVA; $F=85.0$ and 44.3 for FcCa1 and Fc015, respectively, $p<0.05$ ). Significant differences were found between the F. circinatum isolates on the extent of inhibition by all of the Trichoderma spp. (unpaired $t$-test, $p<0.05$ ). In general, the T. hamatum T3 non-volatile compounds were the least effective against both of the F. circinatum isolates. T. asperellum T20 showed the highest inhibition activity against isolate FcCa1, and T. virens T21 and T. harzianum T6 were the most effective inhibitors against isolate Fc015 (Figure 3).
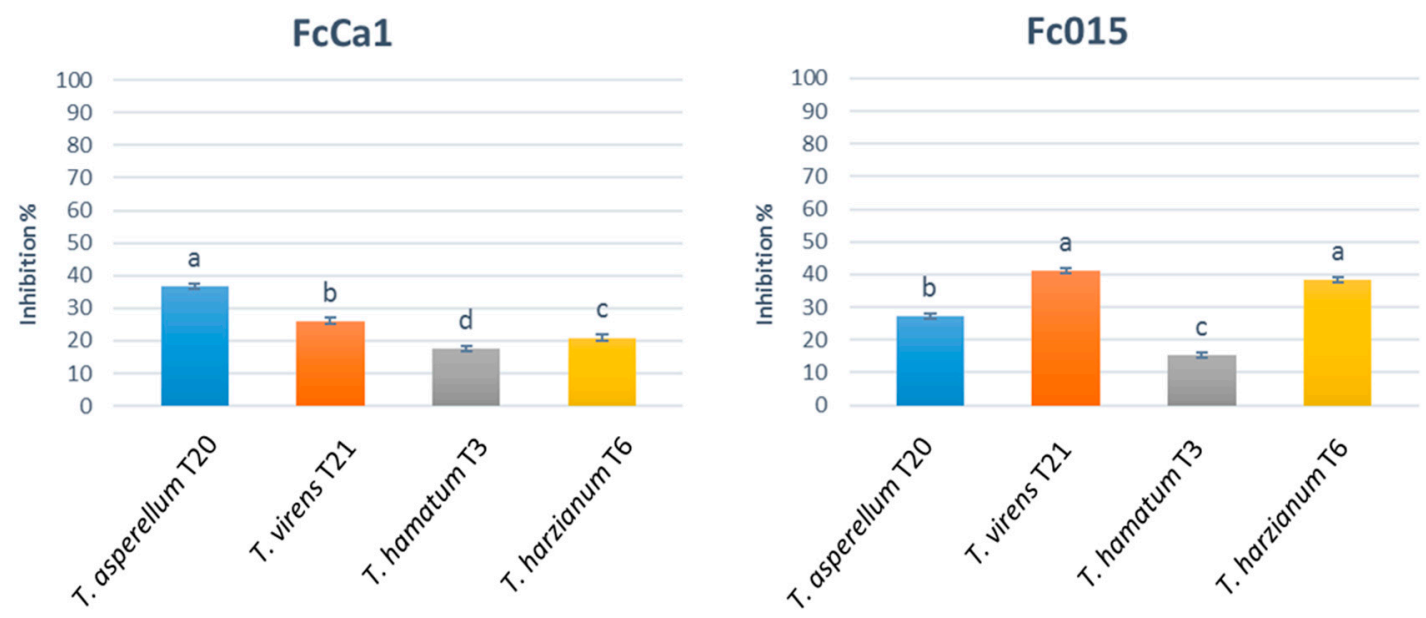

Figure 3. Percent inhibition of F. circinatum (FcCa1 and Fc015) mycelial growth by non-volatile compounds of Trichoderma spp. Different letters indicate significant differences at $p<0.05$, according to Tukey's post-hoc test. Vertical bars indicate SE.

All of the Trichoderma spp. produced volatile compounds, showing a variable inhibition activity of F. circinatum hyphal growth (Figure 4). The percent inhibition of the hyphal growth by all of the Trichoderma isolates ranged between 17 and 22\%, and 14 and 41\% against isolates FcCa1 and Fc015, respectively. The two-way ANOVA highlighted a significant interaction between the two factors, F. circinatum and Trichoderma spp. $(F=8.84, p<0.05)$. Thus, the one-way ANOVA was run for each F. circinatum isolate. Significant differences were found between the F. circinatum isolates on the extent of inhibition by T. asperellum and T. hamatum (unpaired $t$-test, $p<0.05$ ). No significant differences were found between the Trichoderma spp. in the inhibition of mycelial growth of the F. circinatum isolate, FcCa1 (one-way ANOVA; $F=1.02, p>0.05$ ). However, significant differences were found against the isolate, $\mathrm{Fc015}$ (one-way ANOVA; $F=28.72, p<0.05$ ). In general, the T. hamatum T3 volatile compounds were the least effective against both of the F. circinatum isolates, while the T. asperellum T20 and T. virens T21 showed the highest volatile inhibition (Figure 4). 
FcCa1

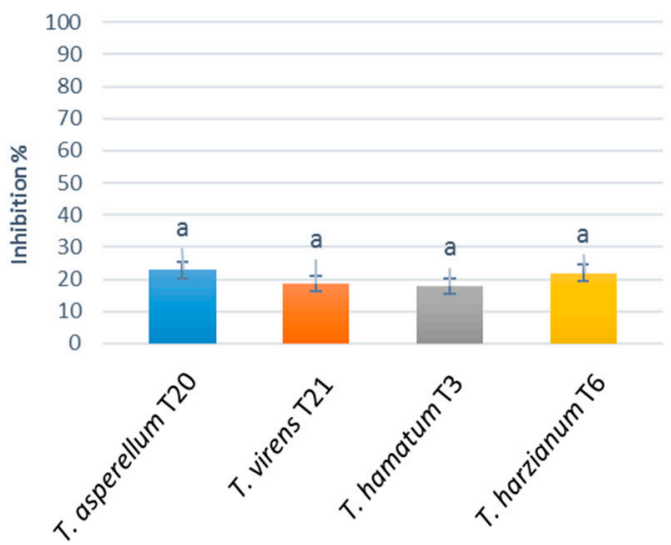

Fc015

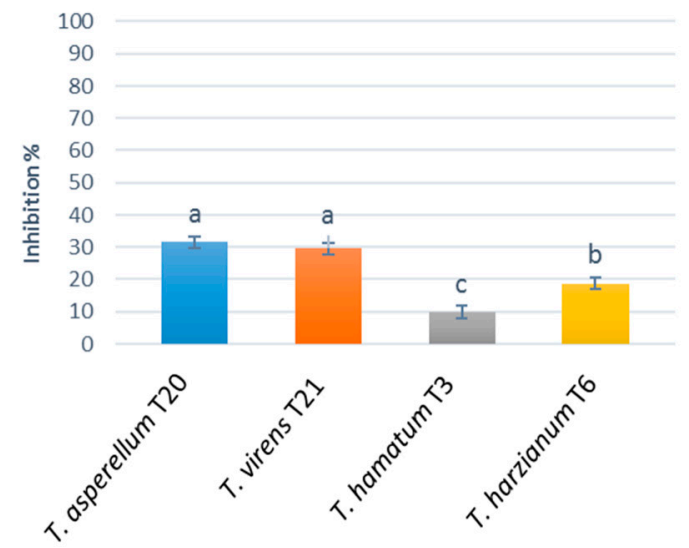

Figure 4. Percent inhibition of F. circinatum (FcCa1 and $\mathrm{Fc015}$ ) mycelial growth by volatile compounds of Trichoderma spp. Different letters indicate significant differences at $p<0.05$, according to Tukey's post-hoc test. Vertical bars indicate SE.

\subsubsection{Biocontrol Activity of F. circinatum in the Seedbed of Pinus radiata}

No significant differences were found between the F. circinatum isolates; thus, the data were combined for the statistical analysis. Pine seeds inoculated with F. circinatum were significantly reduced in germination, in comparison with other treatments and the uninoculated control (one-way ANOVA; $F=10.41, p<0.05$ ) (Table 1). A white mycelium was observed on the surface of the non-germinated seeds. F. circinatum typical coiled sterile hyphae were observed at the light microscopy from the colonies grown on SNA, identical to those of the isolates FcCa1 and Fc015. None of the germinated pine seedlings died in the uninoculated controls, with or without the T-complex treatment. Significant differences were found in the percent of the mortality of the seedlings after two months of growth (one-way ANOVA; $F=97.13, p<0.05$ ). The treatment of the Fusarium-inoculated seed with the T-complex, reduced the mortality four times in comparison to the Fusarium inoculated, non-treated control (Table 1). Taking into account the germination and mortality frequencies both of the F. circinatum isolates, demonstrated to be highly pathogenic with an average of $96.87 \%$ incidence.

Table 1. Percentage of germination and mortality of $P$. radiata seeds inoculated with F. circinatum and treated with the T-complex (combination of T. hamatum T3, T. harzianum T6, T. asperellum T20, and T. virens T21; see Materials and Methods). Different letters in the columns indicate significant differences $(p<0.05)$, according to Tukey's post-hoc test. SE—standard error.

\begin{tabular}{ccc}
\hline & \% Germination \pm SE & \% Seedling Mortality \pm SE $^{\mathbf{1}}$ \\
\hline Non-inoculated control & $78.3 \pm 5.2^{\mathrm{b}}$ & 0 \\
T-complex & $66.6 \pm 5.2^{\mathrm{b}}$ & 0 \\
Fusarium and T-complex & $70.83 \pm 7.52^{\mathrm{b}}$ & $16.5 \pm 3.7^{\mathrm{a}}$ \\
Fusarium & $52.5 \pm 8.51^{\mathrm{a}}$ & $69 \pm 3.7^{\mathrm{b}}$ \\
\hline
\end{tabular}

${ }^{1}$ Once the seed was germinated, it was classified as a seedling and the mortality was recorded.

\subsection{Biocontrol of F. circinatum with BioFence ${ }^{\circledR}$}

\subsubsection{In Vitro Inhibition Tests}

The BioFence ${ }^{\circledR}$ treatments inhibited the mycelial growth of both of the F. circinatum isolates (Figure 5). The three-way ANOVA highlighted a significant interaction among the isolate $\times$ temperature $\times$ dose. Thus, the two-way ANOVA was run for each temperature $\left(10^{\circ} \mathrm{C}\right.$ and $\left.20^{\circ} \mathrm{C}\right)$. The two-way ANOVAs 
indicated that the inhibition was significantly different depending on the dose employed $(F=37.13$, $p<0.05$ at $10^{\circ} \mathrm{C}$; and $F=847.09, p<0.05$ at $\left.20^{\circ} \mathrm{C}\right)$, but not on the $F$. circinatum isolate $(F=0.2, p>0.05$ at $10^{\circ} \mathrm{C}$; and $F=0.3, p>0.05$ at $\left.20^{\circ} \mathrm{C}\right)$. No significant interactions $(p>0.05)$ were found between the factors F. circinatum isolate and BioFence ${ }^{\circledR}$ dose.

$10^{\circ} \mathrm{C}$

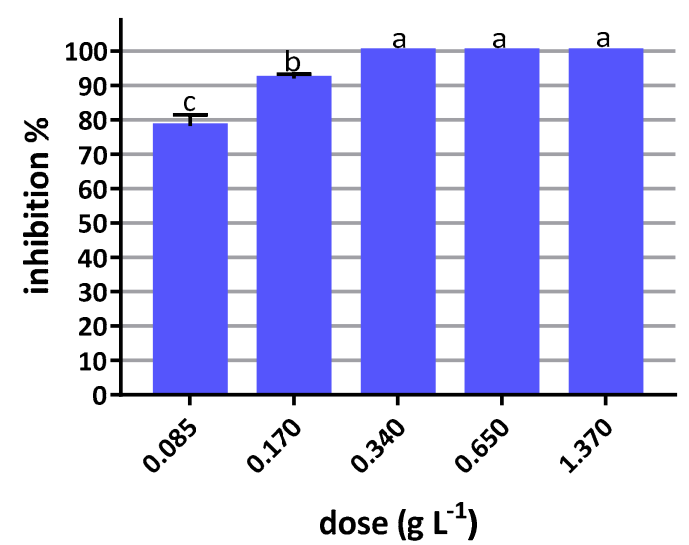

$20^{\circ} \mathrm{C}$

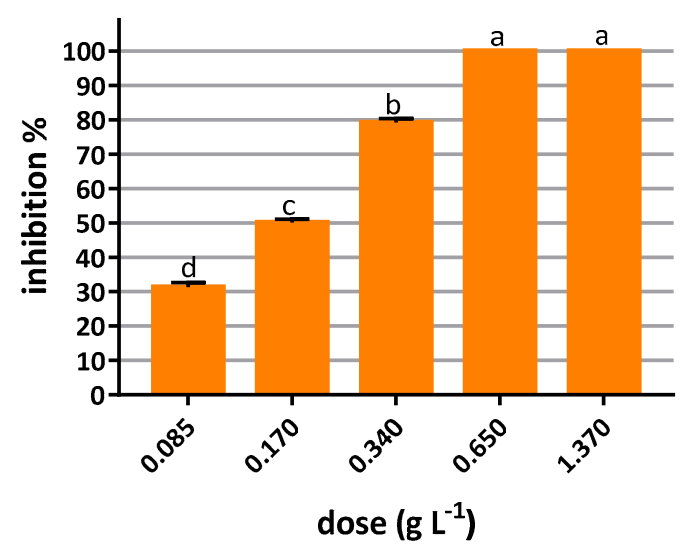

Figure 5. Percent inhibition of F. circinatum mycelial growth at two different temperatures $\left(10^{\circ} \mathrm{C}\right.$ and $\left.20^{\circ} \mathrm{C}\right)$ with the dose of BioFence ${ }^{\circledR} 0.0850,0.17,0.34,0.68$ and $1.37 \mathrm{~g} \mathrm{~L}^{-1}$. No significant differences were found between the isolates $\mathrm{FcCa} 1$ and $\mathrm{Fc}_{\mathrm{c}} 15$; thus, data were combined for the statistical analysis. Different letters indicate significant differences at $p<0.05$ according to Tukey's post-hoc test. Vertical bars $=$ SE.

The dose of $1.37 \mathrm{~g} \mathrm{~L}^{-1}$ was fungicidal as no growth was observed once the pellets were removed and the plates were incubated for 30 days. In contrast, 0.34 and $0.68 \mathrm{~g} \mathrm{~L}^{-1}$ were fungistatic at 10 and $20{ }^{\circ} \mathrm{C}$ respectively, causing $100 \%$ inhibition for 6 days after incubation.

Conidia germination was inhibited after the exposure to various doses of BioFence ${ }^{\circledR}$, and the numbers of colonies decreased with an increase in biofumigant dose (Figure 6). Three-way ANOVA highlighted a significant interaction among isolate $\times$ temperature $\times$ dose. Thus, two-way ANOVA was run for each temperature $\left(10^{\circ} \mathrm{C}\right.$ and $\left.20^{\circ} \mathrm{C}\right)$. Two-way ANOVAs indicated that the inhibition was significantly different depending on the dose employed $\left(F=15.27, p<0.0001\right.$ at $10{ }^{\circ} \mathrm{C}$; and $F=28.05$, $p<0.0001$ at $\left.20^{\circ} \mathrm{C}\right)$, but not on the $F$. circinatum isolate $\left(F=3.35, p>0.05\right.$ at $10^{\circ} \mathrm{C}$; and $F=0.06, p>0.05$ at $\left.20^{\circ} \mathrm{C}\right)$. No significant interactions $(p>0.05)$ were found between the factors $F$. circinatum isolate and BioFence ${ }^{\circledR}$ dose.

Germination was completely inhibited at $0.75,1$, and $2 \mathrm{~g} \mathrm{~L}^{-1}$ at 8 days at all the temperatures studied. 
$10^{\circ} \mathrm{C}$

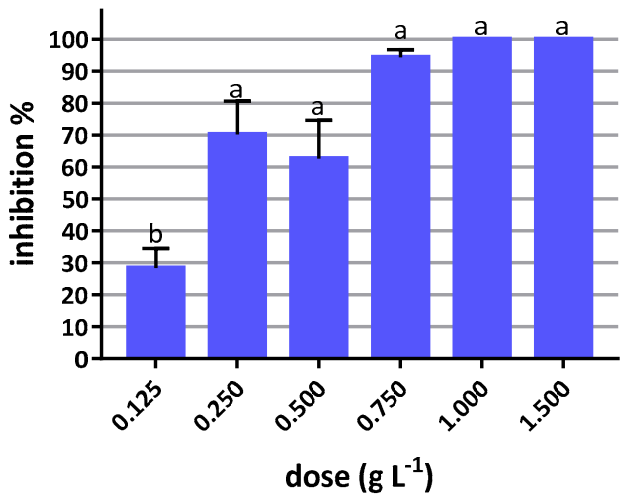

$20^{\circ} \mathrm{C}$

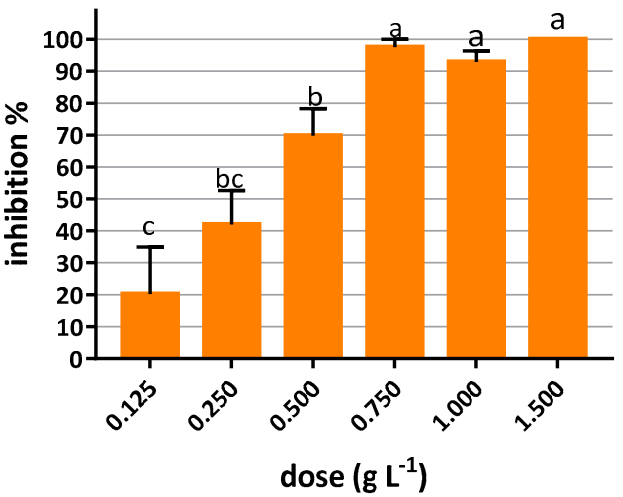

Figure 6. Percent inhibition of F. circinatum conidia germination at two different temperatures $\left(10{ }^{\circ} \mathrm{C}\right.$ and $20^{\circ} \mathrm{C}$ ) with the dose of BioFence ${ }^{\circledR} 0.125,0.25,0.5,0.75,1$, and $1.5 \mathrm{~g} \mathrm{~L}^{-1}$. No significant differences were found between the isolates FcCa1 and Fc015; thus, data were combined for the statistical analysis. Different letters indicate significant differences at $p<0.05$, according to Tukey's post-hoc test. Vertical bars $=$ SE.

To study the effect of temperature on the biofumigation efficacy of the Biofence ${ }^{\circledR}$ pellets, the $\mathrm{EC}_{50}$ was calculated for the inhibition of mycelial growth and conidia germination (Table 2). As no significant differences were found between the isolates, $\mathrm{FCCa} 1$ and $\mathrm{Fc} 015$, in response to the doses of Biofence ${ }^{\circledR}$, the data of the two isolates were combined. Significant differences in inhibition of the mycelial growth were found between the two temperatures studied (extra sum-of-square $F$-test model comparison; $F=399.4, p<0.0001$ ) (Table 2). The $\mathrm{EC}_{50}$ at $10^{\circ} \mathrm{C}$ was almost ten times lower than at $20^{\circ} \mathrm{C}$ (Table 2). Regarding the conidia germination, no differences in inhibition were found between the two temperature studied (extra sum-of-square $F$-test model comparison; $F=1.22, p>0.05$ ) (Table 2).

Table 2. Values of $\mathrm{EC}_{50}\left(\mathrm{~g} \mathrm{~L}^{-1}\right)$ for the inhibition of mycelial growth and the conidia germination of $F$. circinatum by BioFence ${ }^{\circledR}$ at two different temperatures $\left(10{ }^{\circ} \mathrm{C}\right.$ and $\left.20{ }^{\circ} \mathrm{C}\right)$. No significant differences were found between the isolates, FcCa1 and $\mathrm{Fc015}$; thus, the data were combined for the statistical analysis.

\begin{tabular}{|c|c|c|c|c|c|}
\hline & \multicolumn{2}{|c|}{$10^{\circ} \mathrm{C}$} & \multicolumn{2}{|c|}{$20^{\circ} \mathrm{C}$} & \multirow[t]{2}{*}{ Models Comparison ${ }^{2}$} \\
\hline & $\begin{array}{c}\mathrm{EC}_{50} \\
\left(\mathrm{~g} \mathrm{~L}^{-1} \pm \mathrm{SE}\right)\end{array}$ & $\begin{array}{l}\text { Goodness of Fit } \\
\operatorname{Rsq}\left(\mathrm{DF}^{1}\right)\end{array}$ & $\begin{array}{c}\mathrm{EC}_{50} \\
\left(\mathrm{~g} \mathrm{~L}^{-1} \pm \mathrm{SE}\right)\end{array}$ & $\begin{array}{l}\text { Goodness of Fit } \\
\text { Rsq (DF) }\end{array}$ & \\
\hline Mycelial growth & $0.026 \pm 0.003$ & $0.98(69)$ & $0.22 \pm 0.02$ & $0.97(69)$ & $F=399.4 ; p<0.0001$ \\
\hline Conidia germination & $0.3 \pm 0.1$ & $0.76(52)$ & $0.47 \pm 0.15$ & $0.79(53)$ & $F=1.22 ; p>0.05$ \\
\hline
\end{tabular}

${ }^{1} \mathrm{DF}$ - degrees of freedom; ${ }^{2}$ Extra sum-of-square $F$-test.

\subsubsection{Fungicide Effect and Application Timing of Biofence ${ }^{\circledR}$ on Fusarium circinatum In Vitro}

The mycelial growth and conidia germination of the two F. circinatum isolates responded variably to the application timing of BioFence ${ }^{\circledR}$, although the differences were not significant. In the case of the mycelial growth, the concentration used $\left(1,1.5\right.$, and $\left.2 \mathrm{~g} \mathrm{~L}^{-1}\right)$ was fungistatic at $3 \mathrm{~h}, 6 \mathrm{~h}$, and $9 \mathrm{~h}$, and fungicidal at $24 \mathrm{~h}$ and $48 \mathrm{~h}$. In the case of conidia, the germination was inhibited with all of the BioFence ${ }^{\circledR}$ concentrations used, and all of the doses were fungicidal.

\subsubsection{Biocontrol in Pinus radiata Seeds with BioFence ${ }^{\circledR}$}

The number of germinated seeds was recorded after 15 days in the wet chamber. The concentration recommended by the manufacturer $\left(3 \mathrm{~g} \mathrm{~L}^{-1}\right)$ for the biofumigation had no effect on the F. circinatum. Therefore, only the results of the biofumigation with $6 \mathrm{~g} \mathrm{~L}^{-1}$ are shown in Table 3. The biofumigation with BioFence ${ }^{\circledR}$ of the Fusarium-inoculated seeds had a significant effect on the germination, as the 
number of seeds that were germinated doubled when treated. However, the treatment with BioFence ${ }^{\circledR}$ at $6 \mathrm{~g} \mathrm{~L}^{-1}$ showed a significant phytotoxic effect on the non-inoculated seeds. A whitish mycelium of F. circinatum was observed on the surface of the Fusarium-inoculated control seeds or on the radicles of the germinated seeds. Coiled sterile hyphae were observed at light microscopy on the colonies grown on SNA, identical to those observed from the cultures of the isolates FcCa1 and Fc015. None of the non-inoculated control and BioFence ${ }^{\circledR}$-treated seeds had mycelium present. No significant differences were found between the F. circinatum isolates, and the data were combined for the statistical analysis. One-way ANOVA was used, followed by the Tukey post-hoc test; significant differences were found between the treatments $(F=17.28, p<0.05)$.

Table 3. Percentage of germination of the P. radiata seeds inoculated with F. circinatum isolates, FcCa1 and Fc015, and treated with BioFence ${ }^{\circledR}$. Different letters in the column indicate significant differences $(p<0.05)$, according to Tukey's post-hoc test.

\begin{tabular}{cc}
\hline & \% Germination \pm SE \\
\hline Non-inoculated control & $75 \pm 6.4^{\mathrm{a}}$ \\
\hline Non-inoculated control and BioFence $^{\circledR}$ & $51.7 \pm 11.38^{\mathrm{b}}$ \\
\hline Fusarium and BioFence $^{\circledR}$ & $47.8 \pm 11.7^{\mathrm{b}}$ \\
\hline Fusarium & $22.8 \pm 7.2^{\mathrm{c}}$ \\
\hline
\end{tabular}

\section{Discussion}

In this study, the antagonist effect of a selection of Trichoderma isolates, referred to as the T-complex, and the efficacy of the biofumigation with the commercial pellet BioFence ${ }^{\circledR}$, were investigated in vitro and in vivo, to control the pathogen F. circinatum.

The results obtained add $F$. circinatum to the list of pathogens successfully challenged with the T-complex isolates [18], reducing the disease levels of the host plants. The efficacy of Trichoderma spp. as biocontrol agents against F. circinatum is not obvious in the literature. In similar tests conducted on $P$. radiata seeds and seedlings, no effect of $T$. harzianum on the development of the disease was observed [38]. Compost from forest cleaning green waste and T. asperellum strain T34 reduced the incidence of damping-off by F. circinatum in P. radiata seedlings [39], although it was as not possible to discriminate whether such a reduction was due to the suppressiveness of the compost or to the antagonist effect of T. asperellum. In the dual tests carried out in the present study, all of the Trichoderma isolates inhibited the growth of the F. circinatum isolates by more than $50 \%$, with T. asperellum being the most effective and T. virens being the least. A similar extent of inhibition in vitro was reported by Martínez-Álvarez et al. [22], using a different Trichoderma species, T. viride. In the non-volatile inhibition tests, T. hamatum was the least effective against both of the F. circinatum isolates; T. asperellum was the most effective against isolate FcCa1, whereas T. virens and T. harzianum were the most effective against isolate Fc015. With respect to the volatile metabolites, the four Trichoderma isolates showed the same inhibitory effect against the isolate FcCa1, whereas T. asperellum and T. virens were the most effective against the isolate Fc015. Thus, the genotype of the pathogen was a significant factor in determining the biocontrol efficiency of the Trichoderma spp. isolates. As reported by Howell [16], the biocontrol mechanisms used by the Trichoderma species are varied and complex, and their efficacy varies among species, in relation to the pathogens and host. The variability in the efficacy of a single isolate (or species) of Trichoderma to control P. radiata damping-off by F. circinatum has been reported by Martinez-Alvarez et al. [22]. In their studies, the reduction of the seedling mortality by T. viride was conditioned by the pathogen genotype and inoculum concentration of the biocontrol agent. More recently, Martin-Garcia et al. [23], demonstrated a variable efficiency of Trichoderma spp. (i.e., T. viride and T. atroviride) in reducing the post-emergence mortality of the seedlings of Pinus sylvestris L., P. mugo Turra, and Picea abies (L.) Karst, at different doses of F. circinatum inoculum. In the present study, the Trichoderma isolates exerted a variable inhibition of $F$. circinatum mycelial 
growth by direct contact, and volatile and non-volatile compounds, indicating that the mechanisms involved in antagonism are different and often complementary. In the in vivo experiments, the application of Trichoderma spp. combined in a single preparation resulted in a significant reduction in the seedling mortality, with no significant effect of the pathogen genotype. These results support the choice of a combination of antagonists, instead of single ones, to control the F. circinatum in the nursery. Aleandri et al. [18] obtained a better control of lavender root rot caused by Rhizoctonia solani J. G. Kühn, Sclerotinia sclerotiorum (Lib.) de Bary, and Phytophthora nicotianae Breda de Haan, with the application, in a single preparation, of the Trichoderma isolates, compared with each isolate applied alone. Roberts et al. [40] speculated that a combination of biocontrol agents is more likely to have a greater variety of traits responsible for the suppression of one or more pathogens, and is likely to have these traits expressed over a wide range of environmental conditions.

In the in vitro test with BioFence ${ }^{\circledR}$ pellets, two variables were investigated, dose and temperature, to determine the efficacy of the biofumigation and its potential for routine applications in nurseries. The suppression of F. circinatum by BioFence ${ }^{\circledR}$ confirmed the results obtained in previous studies with other Fusarium species, such as Fusarium oxysporum [29,41], F. graminearum Schwabe [42], and F. culmorum (Wm.G. Sm.) Sacc. [43]. The treatment can be lethal to F. circinatum mycelium and even to asexual spores. The $\mathrm{EC}_{50}$ results showed a better efficacy of the conidia germination inhibition or death at $10{ }^{\circ} \mathrm{C}$ than at $20{ }^{\circ} \mathrm{C}$. The effect of temperature on the biofumigation efficacy against different organisms has been reported in several studies, but with contrasting results. In a greenhouse experiment, Steffek et al. [43] showed that the efficacy of the biofumigation against Verticillium dahliae Kleb. and F. culmorum was temperature independent between $8{ }^{\circ} \mathrm{C}$ and $25{ }^{\circ} \mathrm{C}$. Matthiessen and Shackleton [44] reported how the $\mathrm{EC}_{90}$ of different purified ITCs and Brassica tissues against white-fringed weevil larvae decreased as the temperature rose from $5^{\circ} \mathrm{C}$ to $20^{\circ} \mathrm{C}$. In the case of the control of Phytophthora cinnamomi Rand. with BioFence ${ }^{\circledR}$, the $\mathrm{EC}_{50}$ increased as temperature increased [37]. In the studies on the Allyl-ITC (AITC) production by degradation of Brassica juncea (L.) Czern. tissues, Prince et al. [45] observed how the concentration of AITC is constant at $15^{\circ} \mathrm{C}$ overtime, with no significant differences over $24 \mathrm{~h}$. However, at 30 and $45{ }^{\circ} \mathrm{C}$, the concentration of the AITC increased between $0.25 \mathrm{~h}$ and $4 \mathrm{~h}$, and then decreased between $4 \mathrm{~h}$ and $24 \mathrm{~h}$. The authors suggested that the increase in temperature enhanced the volatilization of the AITC. Lim and Tung [46] reported the negative relationship of the permeability coefficients with the temperature for AITC. The higher efficacy at the lower temperatures of biofumigation with BioFence ${ }^{\circledR}$ pellets might be explained by a better solubilization of the ITCs into fungal tissues [37].

While the temperature affected the efficacy of BioFence ${ }^{\circledR}$ against $F$. circinatum at low concentrations, it had no effect at the fungicidal concentration of 1.37 and $0.75 \mathrm{~g} / \mathrm{L}$. This result has practical implications, as it enables the use of biofumigation at lethal concentrations across a wide temperature range, against vegetative and reproductive structures of the pathogen.

The mycelium was more sensible than the conidia to the biofumigation with BioFence ${ }^{\circledR}$, having a lower $\mathrm{EC}_{50}$. Previous studies also evidenced a lower tolerance of mycelium of $R$. solani and S. sclerotiorum to the biofumigation than to the sclerotia $[47,48]$. These observations are consistent with the speculation of Greenhalgh and Mitchell [49], that the activity of propenyl isothiocyanate toward P. nicotianae mycelium should be more deleterious than to sporangia, because the first is an active and the latter is an inactive stage in the fungal development. On the contrary, Smolinski et al. [29] found that the conidial and chlamydospore germination of F. oxysporum was highly susceptible to inactivation by isothiocyanates, while the effect on the mycelial growth was less relevant.

Exposition to biofumigation treatment to obtain a lethal effect on F. circinatum vegetative and reproductive structures represents an additional factor to keep in consideration. In the present study, the lethal effect was achieved in vitro at $24 \mathrm{~h}$. In the post-harvest studies, different times of exposition have been investigated. On pears fruit, the best control of Penicillium expansum Link, causing blue mold, was achieved by exposing the fruits at a dose of $5 \mathrm{mg} \mathrm{L}^{-1}$ allyl-isothiocyanates-enriched atmosphere for $24 \mathrm{~h}$. [50]; Glucoraphanin ITC showed the highest effectiveness at $6 \mathrm{~d}$ at $20^{\circ} \mathrm{C}$ against Monilinia laxa (Aderh. and Ruhland) Honey, Botrytis cinerea, and Mucor piriformis A. Fisch. [51]. 
The allyl-isothiocyanates (AITC) treatment significantly reduced the losses caused by the B. cinerea on

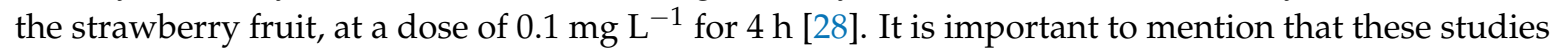
have been used in synthetic AITC enriched atmospheres. In the present study, the B. carinata pellet was used, where the addition of water activates the myrosinases that catalyze the production of ITCs among other compounds.

Pine seeds are an important pathway for the movement of the causal agent of pitch canker [52]. Several chemicals, including fungicides, and physical methods have been evaluated for efficacy to control the F. circinatum on the P. radiata seeds [9,53]. Muñoz et al. [53] reported that chlorothalonil treatments effectively reduced $F$. circinatum incidence on inoculated $P$. radiata seeds, but fludioxonil, metiram, mefenoxam, pyraclostrobin, tebuconazole, thiophanate-methyl, and thiram were considered to be ineffective. Berbegal et al. [9] reported that the treatments with hydrogen peroxide, pyraclostrobin, fluazinam, and imazalil increased the percent of the seed emergence. In the same study, hot water and hydrogen peroxide treatments significantly reduced the F. circinatum contamination on the $P$. radiata seeds, with an overall disease incidence lower than $0.8 \%$ on the seedlings. In the present study, the biofumigation of $P$. radiata seeds with BioFence ${ }^{\circledR}$ for $24 \mathrm{~h}$, had a fungicide effect on the conidia and increased, up to $100 \%$, the number of germinated seeds compared to the inoculated controls, even if a significant detrimental effect on the seed viability was recorded on the uninoculated controls. Although the phytotoxic effect of ITC is reported in the literature [25], other co-factors, such as the pine species, and the age and vigor of the seed lots, can account for the seed viability after chemical and physical treatments [54,55]. Thus, further studies including more variables are necessary to optimize the use of ITCs and to minimize the risk of phytotoxicity. However, biofumigation with BioFence ${ }^{\circledR}$, compared to the other physical and chemical seed treatments, can still be considered a valuable alternative, specifically in the consideration of the ability of the volatile ITCs, to penetrate into the tissues to control the endophytic infections, as evidenced in the studies on the post-harvest treatment [28]. However, this aspect was not considered in the present study, and certainly deserves to be investigated.

In conclusion, the use of the T-complex to limit the $P$. radiata seedling damping-off when being added to the potting mix and of BioFence ${ }^{\circledR}$ in seed disinfection, provide a valid alternative for the production of high-quality nursery plant and seed lots, combining efficacy and environmental sustainability. The use of non-infected seeds and the control of the disease in nurseries are the most effective means to prevent the introduction of F. circinatum into areas currently free of the disease. Finally, the release of new protocols and a method for the sustainable prevention of seed contamination must be carefully considered in the phytosanitary measures stated by National Plant Protection Organizations (NPPO's) and member states, in the case of regulated pests, such as F. circinatum in Europe [56].

Author Contributions: C.M.-R. developed the conceptual ideas, designed the study, conducted the data elaboration, and wrote the paper; G.B. and M.A. developed conceptual ideas, design the study, conducted measurements and data analysis in lab experiments; G.C. contributed in the design of the experiment with the T-complex and in the discussion section; and A.V. supervised the study and wrote the paper.

Funding: This research received no external funding.

Acknowledgments: The study was carried out within the framework of the COST action FP1406 Pine pitch canker-strategies for management of Gibberella circinata in greenhouses and forests (PINESTRENGTH). Carmen Morales-Rodríguez was awarded a Short Term Scientific Mission within the PINESTRENGTH framework, to perform the experiment in the Laboratory of DIBAF, the University of Tuscia (Italy).

Conflicts of Interest: The authors declare no conflict of interest. 


\section{References}

1. Ganley, R.J.; Watt, M.S.; Manning, L.; Iturritxa, E. A global climatic risk assessment of pitch canker disease. Can. J. For. Res. 2009, 39, 2246-2256. [CrossRef]

2. Gordon, T.R.; Swett, C.L.; Wingfield, M.J. Management of Fusarium diseases affecting conifers. Crop Prot. 2015, 73, 28-39. [CrossRef]

3. Evira-Recuenco, M.; Iturritxa, E.; Raposo, R. Impact of seed transmission on the infection and development of pitch canker disease in Pinus radiata. Forests 2015, 6, 3353-3368. [CrossRef]

4. Dwinell, L.D.; Barrows-Broaddus, J.B.; Kuhlman, E.G. Pitch canker: A disease complex. Plant Dis. 1985, 69, 270-276. [CrossRef]

5. Viljoen, A.; Wingfield, M.; Marasas, W. First report of Fusarium subglutinans f. sp. pini on pine seedlings in South Africa. Plant Dis. 1994, 78, 309-312. [CrossRef]

6. Storer, A.; Gordon, T.; Clark, S. Association of the pitch canker fungus, Fusarium subglutinans f. sp. pini with Monterey pine seeds and seedlings in California. Plant Pathol. 1998, 47, 649-656. [CrossRef]

7. Huang, J.; Kuhlman, E. Fungi associated with damping-off of slash pine seedlings in Georgia. Plant Dis. 1990, 74, 27-30. [CrossRef]

8. Wingfield, M.; Hammerbacher, A.; Ganley, R.; Steenkamp, E.; Gordon, T.; Wingfield, B.; Coutinho, T. Pitch canker caused by Fusarium circinatum-A growing threat to pine plantations and forests worldwide. Australas. Plant Pathol. 2008, 37, 319-334. [CrossRef]

9. Berbegal, M.; Landeras, E.; Sánchez, D.; Abad-Campos, P.; Pérez-Sierra, A.; Armengol, J. Evaluation of Pinus radiata seed treatments to control Fusarium circinatum: Effects on seed emergence and disease incidence. For. Pathol. 2015, 45, 525-533. [CrossRef]

10. Garbelotto, M. Molecular analyses to study invasions by forest pathogens: Examples from Mediterranean ecosystems. Phytopathol. Mediterr. 2009, 47, 183-203.

11. Berbegal, M.; Pérez-Sierra, A.; Armengol, J.; Grünwald, N. Evidence for multiple introductions and clonality in Spanish populations of Fusarium circinatum. Phytopathology 2013, 103, 851-861. [CrossRef] [PubMed]

12. Carey, W.; Oak, S.; Enebak, S. Pitch canker ratings of longleaf pine clones correlate with Fusarium circinatum infestation of seeds and seedling mortality in containers. For. Pathol. 2005, 35, 205-212. [CrossRef]

13. Du Fretay, G.; Fritsch, F. Alterbromide, dissemination of sustainable alternatives to methyl bromide in soil disinfestation and in post-harvest. Acta Hortic. 2009, 883, 113-116. [CrossRef]

14. Cooney, J.; Lauren, D. Trichoderma/pathogen interactions: Measurement of antagonistic chemicals produced at the antagonist/pathogen interface using a tubular bioassay. Lett. Appl. Microbiol. 1998, 27, 283-286. [CrossRef] [PubMed]

15. Khan, M.R.; Khan, S.M.; Mohiddin, F.A. Biological control of Fusarium wilt of chickpea through seed treatment with the commercial formulation of Trichoderma harzianum and/or Pseudomonas fluorescens. Phytopathol. Mediterr. 2004, 43, 20-25.

16. Howell, C. Mechanisms employed by Trichoderma species in the biological control of plant diseases: The history and evolution of current concepts. Plant Dis. 2003, 87, 4-10. [CrossRef]

17. Sivasithamparam, K.; Ghisalberti, E. Secondary metabolism in Trichoderma. In Trichoderma and Gliocladium. Volume 1: Basic Biology, Taxonomy and Genetics; CRC Press: Boca Raton, FL, USA, 2014.

18. Aleandri, M.P.; Chilosi, G.; Bruni, N.; Tomassini, A.; Vettraino, A.M.; Vannini, A. Use of nursery potting mixes amended with local Trichoderma strains with multiple complementary mechanisms to control soil-borne diseases. Crop Prot. 2015, 67, 269-278. [CrossRef]

19. Martín-Pinto, P.; Pajares, J.; Nanos, N.; Diez, J. Site and seasonal influences on the fungal community on leaves and stems of Pinus and Quercus seedlings in forest nurseries. Sydowia 2004, 56, 243-257.

20. Hohmann, P.; Jones, E.E.; Hill, R.A.; Stewart, A. Understanding Trichoderma in the root system of Pinus radiata: Associations between rhizosphere colonization and growth promotion for commercially grown seedlings. Fungal. Biol. 2011, 115, 759-767. [CrossRef] [PubMed]

21. Moraga-Suazo, P.; Opazo, A.; Zaldúa, S.; González, G.; Sanfuentes, E. Evaluation of Trichoderma spp. and Clonostachys spp. strains to control Fusarium circinatum in Pinus radiata seedlings. Chil. J. Agric. Res. 2011, 71, 412-417. [CrossRef]

22. Martínez-Álvarez, P.; Alves-Santos, F.M.; Diez, J.J. In vitro and in vivo interactions between Trichoderma viride and Fusarium circinatum. Silva Fenn. 2012, 46, 303-316. [CrossRef] 
23. Martín-García, J.; Paraschiv, M.; Flores-Pacheco, J.A.; Chira, D.; Diez, J.J.; Fernández, M. Susceptibility of several northeastern conifers to Fusarium circinatum and strategies for biocontrol. Forests 2017, 8, 318. [CrossRef]

24. Sarwar, M.; Kirkegaard, J. Biofumigation potential of brassicas: II. Effect of environment and ontogeny on glucosinolate production and implications for screening. Plant Soil 1998, 201, 91-101. [CrossRef]

25. Brown, P.D.; Morra, M.J. Control of soil-borne plant pests using glucosinolate-containing plants. Adv. Agron. 1997, 61, 168-231.

26. Kirkegaard, J.A.; Sarwar, M.; Matthiessen, J.N. Assessing the biofumigation potential of crucifers. Acta Hortic. 1998, 459, 105-112. [CrossRef]

27. Mehra, L.; MacLean, D.; Shewfelt, R.; Smith, K.; Scherm, H. Effect of postharvest biofumigation on fungal decay, sensory quality, and antioxidant levels of blueberry fruit. Postharvest Biol. Technol. 2013, 85, 109-115. [CrossRef]

28. Ugolini, L.; Martini, C.; Lazzeri, L.; D’Avino, L.; Mari, M. Control of postharvest grey mould (Botrytis cinerea Pers.: Fr.) on strawberries by glucosinolate-derived allyl-isothiocyanate treatments. Postharvest Biol. Technol. 2014, 90, 34-39. [CrossRef]

29. Smolinska, U.; Morra, M.; Knudsen, G.; James, R. Isothiocyanates produced by Brassicaceae species as inhibitors of Fusarium oxysporum. Plant Dis. 2003, 87, 407-412. [CrossRef]

30. Nirenberg, H.I.; O'Donnell, K. New Fusarium species and combinations within the Gibberella fujikuroi species complex. Mycologia 1998, 90, 434-458. [CrossRef]

31. Morton, D.; Stroube, W. Antagonistic and stimulatory effects of soil microorganisms upon Sclerotium rolfsii. Phytopathology 1955, 45, 417-420.

32. Lahlali, R.; Hijri, M. Screening, identification and evaluation of potential biocontrol fungal endophytes against Rhizoctonia solani AG3 on potato plants. FEMS Microbiol. Lett. 2010, 311, 152-159. [CrossRef] [PubMed]

33. Dennis, C.; Webster, J. Antagonistic properties of species-groups of Trichoderma: II. Production of volatile antibiotics. Trans. Br. Mycol. Soc. 1971, 57, 41-44. [CrossRef]

34. Ioos, R.; Fourrier, C.; Iancu, G.; Gordon, T.R. Sensitive detection of Fusarium circinatum in pine seed by combining an enrichment procedure with a real-time polymerase chain reaction using dual-labeled probe chemistry. Phytopathology 2009, 99, 582-590. [CrossRef] [PubMed]

35. EPPO. Pm 7/91(1): Gibberella circinata. EPPO Bull. 2009, 39, 298-309.

36. Lazzeri, L.; Curto, G.; Leoni, O.; Dallavalle, E. Effects of glucosinolates and their enzymatic hydrolysis products via myrosinase on the root-knot nematode Meloidogyne incognita (Kofoid et White) chitw. J. Agric. Food Chem. 2004, 52, 6703-6707. [CrossRef] [PubMed]

37. Morales-Rodríguez, C.; Vettraino, A.; Vannini, A. Efficacy of biofumigation with Brassica carinata commercial pellets $\left(\right.$ BioFence ${ }^{\circledR}$ ) to control vegetative and reproductive structures of Phytophthora cinnamomi. Plant Dis. 2016, 100, 324-330. [CrossRef]

38. Martínez-Álvarez, P.; Alves-Santos, F.M.; Díez, J.J.J. Efecto de Trichoderma harzianum sobre el damping off causado por Fusarium circinatum en plántulas de Pinus radiata. In Proceedings of the XV Congreso de la Sociedad Española de Fitopatología, Vitoria-Gasteiz, Spain, 27 September-1 October 2010.

39. López-López, N.; Segarra, G.; Vergara, O.; López-Fabal, A.; Trillas, M.I. Compost from forest cleaning green waste and Trichoderma asperellum strain $\mathrm{t} 34$ reduced incidence of Fusarium circinatum in Pinus radiata seedlings. Biol. Control 2016, 95, 31-39. [CrossRef]

40. Roberts, D.P.; Lohrke, S.M.; Meyer, S.L.; Buyer, J.S.; Bowers, J.H.; Baker, C.J.; Li, W.; de Souza, J.T.; Lewis, J.A.; Chung, S. Biocontrol agents applied individually and in combination for suppression of soilborne diseases of cucumber. Crop Prot. 2005, 24, 141-155. [CrossRef]

41. Gilardi, G.; Moizio, M.; Gullino, M.L.; Garibaldi, A. Use of different soil amendments to control fusarium wilt of lettuce. Prot. Delle Colt. 2013, 2, 74.

42. Sarwar, M.; Kirkegaard, J.; Wong, P.; Desmarchelier, J. Biofumigation potential of brassicas. 3. In vitro toxicity of isothiocyanates to soil-borne fungal pathogens. Plant Soil (Netherlands) 1998, 201, 103-112. [CrossRef]

43. Steffek, R.; Spornberger, A.; Stich, K.; Lazzeri, L. The use of brassicas to reduce inoculum potential of soil-borne pests in Austrian horticulture. In Proceedings of the International Symposium on Horticulture in Europe, Vienna, Austria, 17-20 Febuary 2008.

44. Matthiessen, J.N.; Shackleton, M.A. Biofumigation: Environmental impacts on the biological activity of diverse pure and plant-derived isothiocyanates. Pest Manag. Sci. 2005, 61, 1043-1051. [CrossRef] [PubMed] 
45. Price, A.J.; Charron, C.S.; Saxton, A.M.; Sams, C.E. Allyl isothiocyanate and carbon dioxide produced during degradation of Brassica juncea tissue in different soil conditions. HortScience 2005, 40, 1734-1739.

46. Lim, L.T.; Tung, M.A. Vapor pressure of allyl isothiocyanate and its transport in pvdc/pvc copolymer packaging film. J. Food Sci. 1997, 62, 1061-1062. [CrossRef]

47. Yulianti, T.; Sivasithamparam, K.; Turner, D. Response of different forms of propagules of Rhizoctonia solani AG2-1 (ZG5) exposed to the volatiles produced in soil amended with green manures. Ann. Appl. Biol. 2006, 148, 105-111. [CrossRef]

48. Kurt, Ş.; Güneş, U.; Soylu, E.M. In vitro and in vivo antifungal activity of synthetic pure isothiocyanates against Sclerotinia sclerotiorum. Pest Manag. Sci. 2011, 67, 869-875. [CrossRef] [PubMed]

49. Greenhalgh, J.; Mitchell, N. The involvement of flavor volatiles in the resistance to downy mildew of wild and cultivated forms of Brassica oleracea. New Phytol. 1976, 77, 391-398. [CrossRef]

50. Mari, M.; Leoni, O.; Iori, R.; Cembali, T. Antifungal vapor-phase activity of allyl-isothiocyanate against Penicillium expansum on pears. Plant Pathol. 2002, 51, 231-236. [CrossRef]

51. Mari, M.; Iori, R.; Leoni, O.; Marchi, A. Bioassays of glucosinolate-derived isothiocyanates against postharvest pear pathogens. Plant Pathol. 1996, 45, 753-760. [CrossRef]

52. Gordon, T.; Storer, A.; Wood, D. The pitch canker epidemic in California. Plant Dis. 2001, 85, 1128-1139. [CrossRef]

53. Muñoz López, C.; Cuervo Sánchez, E.; Ampudia Díaz, M.; Gastón González, A.; Peñuelas Rubira, J.; Iglesias Sauce, S.; Herrero Sierra, N. Control químico de Fusarium circinatum Niremberg \& O’Donnell en semillas del género Pinus. In Proceedings of the $5^{\circ}$ Congreso Forestal Español, Ávila, Spain, 21-25 September 2009.

54. Baker, R. Thermotherapy of planting material. Phytopathology 1962, 52, 1244-1255.

55. Barnett, J.P. Sterilizing southern pine seeds with peroxide. Tree Plant. Notes 1976, 27, 17-19.

56. Vettraino, A.M.; Potting, R.P.J.; Raposo, R. EU legislation on forest plant health: An overview with a focus on Fusarium circinatum. Forests. in press.

(C) 2018 by the authors. Licensee MDPI, Basel, Switzerland. This article is an open access article distributed under the terms and conditions of the Creative Commons Attribution (CC BY) license (http:/ / creativecommons.org/licenses/by/4.0/). 